\title{
The use of driving impairing medicines: a European survey
}

\author{
Silvia Ravera • Sylvia A. Hummel • Pieter Stolk • \\ Rob E. Heerdink • Lolkje T. W. de Jong-van den Berg • \\ Johan J. de Gier
}

Received: 9 March 2009 /Accepted: 25 June 2009/Published online: 21 July 2009

(C) The Author(s) 2009. This article is published with open access at Springerlink.com

\begin{abstract}
Aim To analyse the consumption of a number of medicines with a known potential for increasing the risk of road traffic accidents in the general population of Europe.

Methods Questionnaires were distributed through the European Drug Utilization Research Group (EuroDURG) and Post-Innovation Learning through Life-events of drugs (PILLS) networks. A total of 30 countries (the current EU Member States, Iceland, Norway and Switzerland) were asked to supply data on the use of driving impairing medicines for the period 2000-2005, aggregated at the level of the active substance and presented in Defined Daily Doses (DDDs) per 1000 inhabitants per day.
\end{abstract}

S. Ravera $\cdot$ J. J. de Gier $(\bowtie)$

Department of Pharmacotherapy and Pharmaceutical Care,

University of Groningen,

Antonius Deusinglaan 1,

9713 AV Groningen, The Netherlands

e-mail: degiercs@wxs.nl

e-mail: j.j.de.gier@rug.nl

\section{S. A. Hummel}

Department of Pharmacokinetics, Toxicology and Targeting,

University of Groningen,

Antonius Deusinglaan 1,

9713 AV Groningen, The Netherlands

P. Stolk $\cdot$ R. E. Heerdink

Division of Pharmacoepidemiology and Pharmacotherapy,

Utrecht Institute for Pharmaceutical Sciences, Utrecht University,

Sorbonnelaan 16,

3584 CA Utrecht, The Netherlands

L. T. W. de Jong-van den Berg

Department of Pharmacoepidemiology and Pharmacoeconomics,

University of Groningen,

Antonius Deusinglaan 1,

9713 AV Groningen, The Netherlands
Results National utilization data were provided by 12 of the 30 countries. Based on these data, a considerable increase in consumption was only seen for the antidepressants and the selective serotonin reuptake inhibitors. A slight increase, decrease or no increase was seen for the rest of the drugs studied (i.e. opioids, antipsychotics, anxiolytics, hypnotics and sedatives, drugs that are used in addictive disorders and antihistamines). Limitations were encountered when data on driving impairing medicines were compared between countries (e.g. variation in the data sources and providers, population coverage, inclusion of hospital data, use of divergent ATC/DDD versions) and, therefore, a crossnational comparison could not be performed.

Conclusions During the study period, trends within countries showed slight to no increase in the consumption of selected medicinal drug groups, with the exception of the antidepressants and the selective serotonin reuptake inhibitors: they showed a remarkable increased use during the study time-frame. Our results illustrate that it is still difficult to perform a valid and comprehensive collection of drug utilization data on driving impairing medicines. Therefore, efforts to harmonize data collection techniques are required and recommended.

Keywords Bias · Driving impairing medicines ·

Drug utilization · European survey

\section{Introduction}

In the year 2000, more than 40,000 people in the European Union (EU) were killed in road accidents and more than 1.7 million were injured [1]. An increasing proportion of these road accidents can be attributed to the use of psychoactive substances (i.e. alcohol, drugs and certain medicines), with 
the use of drugs and medicines increasing proportionally over the years [2]. Consequently, a number of active steps must be taken to gain better insight into this relevant societal problem and introduce appropriate countermeasures.

In 2001, the European Commission set the ambitious goal of halving the number of road deaths between 2003 and 2010 (EU Road Safety Target, White Paper) [3]. To meet this goal, the Commission launched the 4-year DRiving Under the Influence of Drugs, alcohol and medicines (DRUID) project in October 2006 [4]. The objective of this integrated European project is to provide scientific support to the EU transport policy of reaching the 2010 road safety target. However, critical information on the amount of driving impairing medicinal products that are consumed by the European population currently does not exist. Such information is crucial as input for the future planning and successful implementation of the DRUID project.

The aim of the study reported here was to describe the use of some psychotropic medicines and some frequently used medicines with Central Nervous System (CNS) side effects in a non-hospitalized EU population between 2000 and 2005. The consumption data were collected to detect trends that illustrate an increased or decreased utilization of the most relevant medicinal drug groups with known accident risk potentials in the individual countries.

\section{Methods}

All current EU member states as well as other countries of the wider European region (i.e. Iceland, Norway and Switzerland) were invited to supply data on the use of medicines of interest in their country. These countries were approached through two international scientific networksthe Post-Innovation Learning through Life-events of drugs (PILLS) of Utrecht University, the Netherlands, and the European Drug Utilization Research Group (EuroDURG) [5] — or directly via public websites when possible (i.e. Scandinavian countries and the Netherlands). The data were requested for the time period 2000-2005; however, if data were only available for part of the study period, responses were still included in the study. Drug consumption data were presented by the Anatomical Therapeutic Chemical (ATC) Classification System, as recommended by the World Health Organization (WHO) [6].

The included ATC subgroups (Table 1) cover the most frequently used psychotropic medicines and medicines with CNS side effects that are known to be of relevance for traffic safety [7-12]. Glucose-lowering medicines and antiepileptic drugs, also known to be potentially impairing, were excluded from the selection for this study because extensive procedures are in place for the regulation of driving while using these medicines [13].
Table 1 Selected groups of psychotropic medicines and medicines with central nervous system side effects

Anatomical Therapeutic Chemical Classification System

N02A: Opioids (total group)

N05A: Antipsychotics

N05B: Anxiolytics

N05C: Hypnotics and sedatives

N06A: Antidepressants (total group)

N06AA: Non-selective monoamine reuptake inhibitors

N06AB: Selective serotonin reuptake inhibitors

N07B: Drugs used in addictive disorders (total group)

N07BA02: Bupropion ${ }^{\mathrm{a}}$

N07BC02: Methadone ${ }^{\mathrm{a}}$

N07BC03: Levacetylmethadol ${ }^{\mathrm{a}}$

R06A: Antihistamines for systemic use (total group)

R06AE: Piperazine derivatives

R06AX: Other antihistamines for systemic use

${ }^{a}$ These substances changed therapeutic subgroups within the time frame of this research question. The old ATC codes are N06AX12, bupropion; N02AC06, levacethylmethadol; N02AC02, methadone.

Consumption was expressed in Defined Daily Doses $(\mathrm{DDDs})^{1}$ per 1000 inhabitants per day or as the total number of DDDs per year accompanied by the number of inhabitants for the matching periods and region(s). The DDD/1000 inhabitants per day measure was chosen since it is a common unit of measurement tools used to present drug utilization statistics, and it enables international comparisons of drug use and evaluations of trends in drug use over time [6]. Consumption data on hospital care were not requested. Information on the coverage of the data and the sources of the data were requested (e.g. wholesaler data, reimbursement data, pharmacy sale data, etc.) (Table 2).

The ACT code of a small number of the medicines of interest for this study was changed during the study period 2000-2005 (Table 1). Levoceterizine remained within the same therapeutic subgroup, while bupropion, levacetylmethadol and methadone were changed to a different therapeutic subgroups [14]. In order to avoid bias, we requested the consumption data on these three substances separately. Lastly, the DDDs of four substances (bezitramide, fentanyl, hydromorphone and oxycodone) changed during the time frame of this retrospective study. We were unable to correct for the impact of these DDD changes because specific information was lacking.

\footnotetext{
${ }^{1}$ The DDD is the assumed average maintenance dose per day for a drug used for its main indication in adults. The DDD is a unit of measurement and, therefore, it does not reflect precisely the recommended or prescribed daily dose [6].
} 


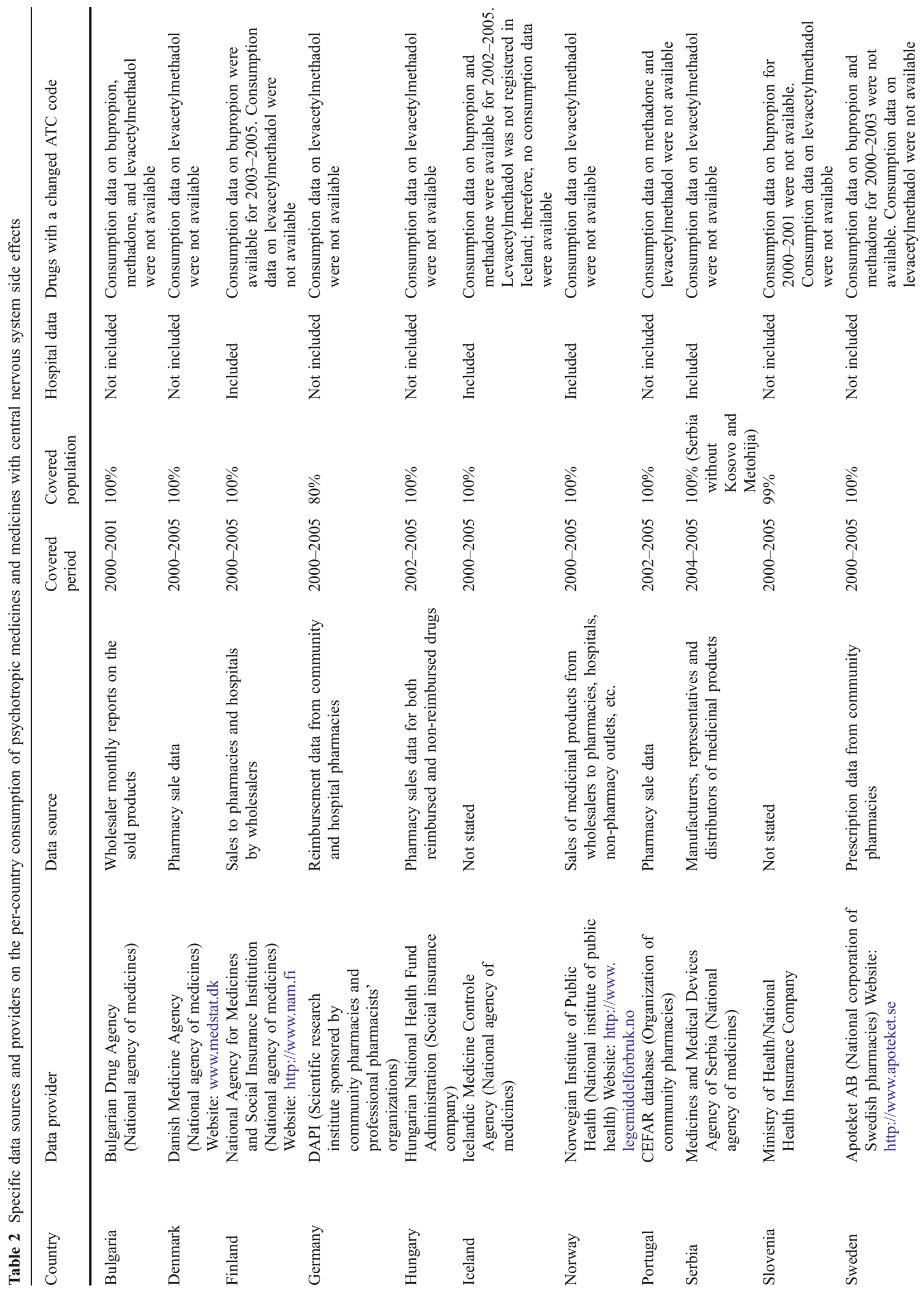




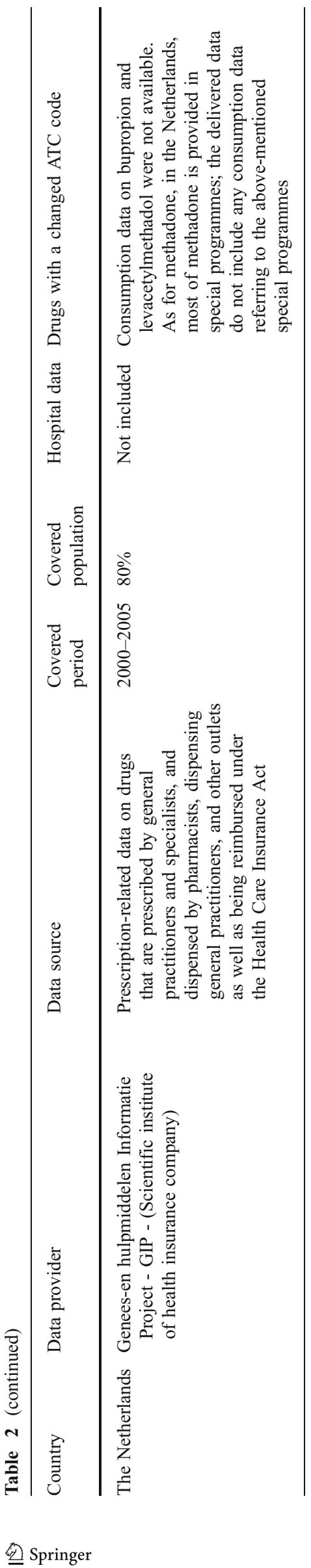

\section{Results}

Thirty countries were approached through the PILLS and EuroDURG networks and public websites. Data from 13 countries were obtained (Bulgaria, Czech Republic, Denmark, Finland, Germany, Hungary, Iceland, Norway, Portugal, Serbia, Slovenia, Sweden and the Netherlands). The response rate was 57\%. Data from Czech Republic were not included in this study as they did not meet the study criteria (i.e. the medicinal products were aggregated at a brand level, and consumption was expressed in number of sold packages). Consequently, all data referred to hereafter have been obtained from the remaining $12 \mathrm{EU}$ data providers.

Data providers and type of data

An overview of the specific data providers per country is reported in Table 2. Data providers comprised national agencies of medicines, national institutes of public health, social insurance companies, ambulatory care data collected by organizations of community pharmacies, ministries of health, national health insurance companies and scientific institutes of health insurance companies. Seven countries (Bulgaria, Denmark, Finland, Germany, Norway, Sweden and the Netherlands) provided the data as DDD/1000 inhabitants per day; the remaining countries (Hungary, Iceland, Portugal, Serbia and Slovenia) provided the number of DDDs together with the estimated covered population.

Population coverage

Nine countries provided data covering $100 \%$ of the their respective population, and three countries (Germany, Slovenia and the Netherlands) could not provide consumption data that covered $100 \%$ of their respective population.

Hospital data

Hospital consumption data were neither requested nor included in this study. However, for some countries (Finland, Iceland, Norway and Serbia), it was not possible to separate the total data from ambulatory and hospital care data.

Medicinal drug utilization trends

The data on the use of psychotropic medicines and medicines with CNS side effects are presented in Table 3. This table gives an overview of the use of the selected drug classes in 2005 and an indication of the consumption trends in 2000-2005. It can be seen that the consumption of these medicinal products varied across Europe. In general, a 


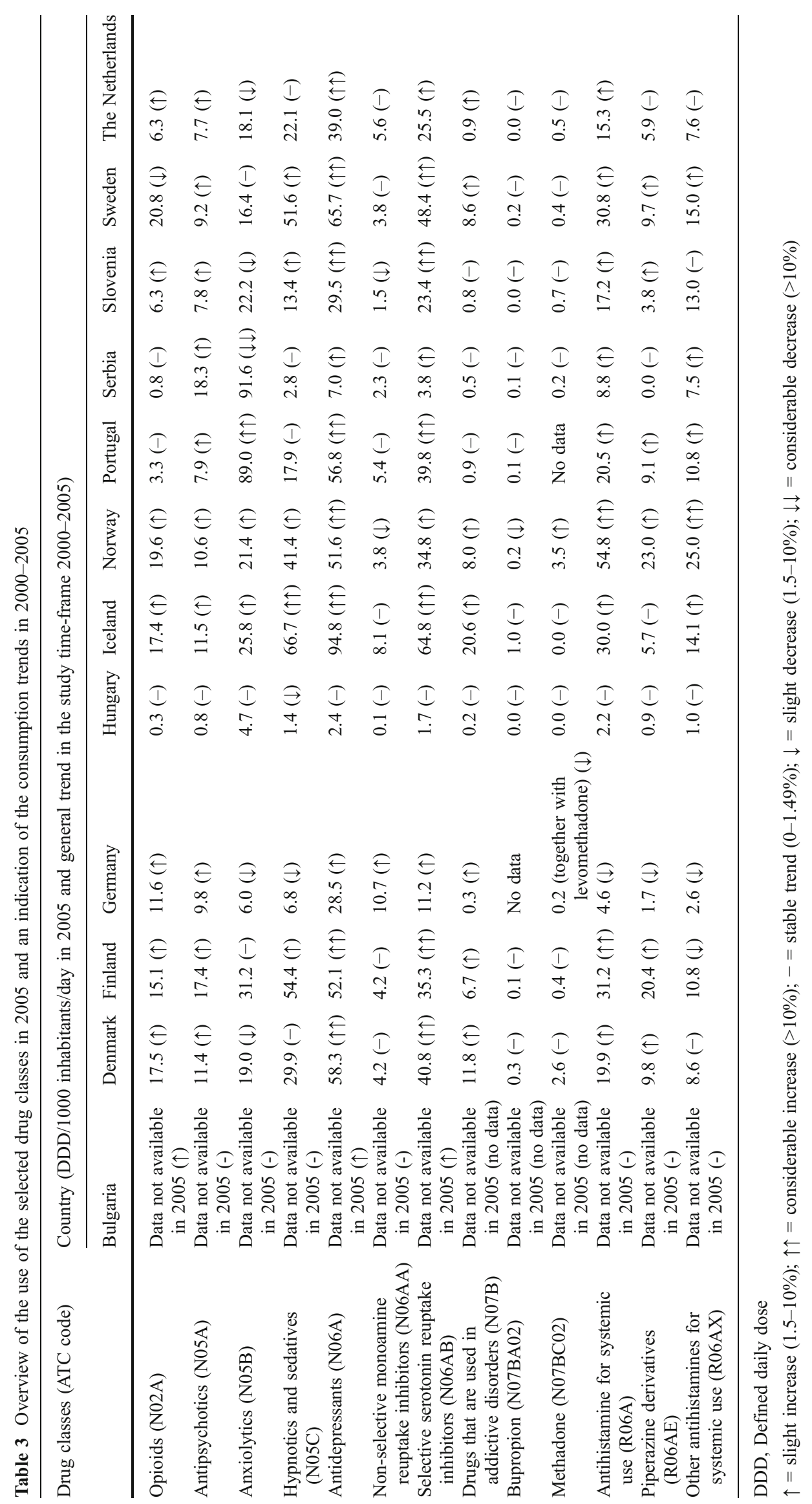


significative upward trend was only found for two of the medicinal product classes of interest, namely the antidepressants and the Selective Serotonin Reuptake Inhibitors (SSRIs).

The consumption data showed an increase in the use of antidepressants in 11 countries between 2000 and 2005. A stable trend in antidepressant use was observed in Hungary.

There was a remarkable increase in the consumption of SSRIs in six of the 12 countries that provided data, namely Denmark, Finland, Iceland, Portugal, Slovenia and Sweden. The remaining countries showed a slight increase in the use of these active substances, with the exception of Hungary where a stable trend was observed.

A slight increase, decrease or no increase at all in the use of the drugs studied was found for most of the countries for which data were obtained. Our analysis of German consumption data revealed a considerable decrease in the consumption of antihistamines.

Finally, some unusual patterns of methadone use were observed in Denmark, Norway and Slovenia in the form of an irregular consumption pattern. In general, there was a rather large variation in the consumption of this medicine in these countries over the period of interest.

\section{Discussion}

To the best of our knowledge, this is the first study carried out on the general population of Europe that focuses on the consumption of a number of frequently used medicinal products with a known potential to increase the risk of road traffic accidents. Our results indicate that the overall utilization of psychotropic medicines and medicines with CNS side effects has slightly increased, decreased or not increased at all in Europe between 2000 and 2005.

Based on the national data that were made available to us, only the consumption of antidepressants and SSRIs showed a considerable increase during the study time interval. The increased use of antidepressants is probably associated to an increase in the consumption of SSRIs. This trend was detected in all countries, with the exception of Hungary, where a stable trend was registered during the years of interest. In some countries, the increase in the use of SSRIs may result from the current clinical practice guidelines that recommend SSRIs as the first-line treatment for panic and generalized anxiety disorders, instead of benzodiazepines [15-17]. However, it should be noted that our figures indicated that there had been no significant decline in benzodiazepine use between 2000 and 2005.

Our data also indicate an irregular pattern of methadone use in Denmark, Norway and Slovenia that deserves attention. These trends may be explained either by the primary utilization of this drug (i.e. maintenance antiaddictive use in patients addicted to opioids) and the consequent difficulties in obtaining valid consumption data or by the various biases that could have potentially affected the data collection procedures.

Contrary to expectations, a reduction in the use of antihistamines was found in the German consumption data. This finding may be explained by the implementation of new legislation, the so-called GMG, in 2004 [18]. Part of this legislation involved a change in the reimbursement regulations for Over-The-Counter (OTC)-pharmaceuticals and, for most indications, OTC products were no longer reimbursed by the respective health insurance system, but rather had to be paid by patients themselves. The consumption of a number of OTC products may have been slightly affected as a result.

An interesting result of our study is that, according to our figures, the consumption of the medicines of interest in the Scandinavian countries often appeared to be much higher than that in the other European countries. Considering that these countries are well known for their rational and conservative prescription practice [19] as well as the fact that they have a long history and experience in data collection [20], we suggest that the most probable reason for this is that Scandinavian countries are able to deliver more reliable and complete data on medicinal product consumption than some of the other countries.

A number of significant limitations to this study need to be considered. An important limitation may lie in the incompleteness of data and in the non-availability of information. In terms of the data collection process, the availability of a cross-national collection system based on the same data sources and data providers would provide more reliable and complete data. However, such a system does not exist, and, as a consequence, the differences in the collection and reporting of data may have compromised the validity of the drug utilization data.

Regarding the issue of incomplete data, it is interesting to observe that, for example, our findings on anxiolytic and antipsychotic drug use in Serbia do not support the findings of a previous study that showed a considerably lower consumption of these two drug classes [21]. This inconsistency may be related to the use of different data sources and providers. The same observations may also be valid for another drug utilization study conducted in Portugal that showed a lower use of hypnotics and sedatives than did our study [22]. However, it is important to emphasize that the discrepancies between the latter study and our study are less remarkable. Moreover, it is relevant to note that our findings on axiolytic use in Portugal are consistent with those described by Furtado and Teixeira [22].

Another limitation may involve population coverage. Nine countries were able to provide consumption data 
that covered the whole population and three countries (Germany, Slovenia and the Netherlands) could not. However, even in data collection systems where $100 \%$ of the population is supposed to be covered, census bias cannot be completely ruled out. This bias may be due, for example, to underdetection in the case of countries where the reimbursement system does not cover the whole population (in data collection systems based on reimbursement data), slight variations in the exact number of insured people (in data collection systems referring to consumption data from insurance companies), missing or incorrect information in the data source from which information on drug use is obtained, among others.

Drug coverage may also have compromised our drug utilization data. In countries where the drug of interest is obtainable OTC, consumption may have been underestimated, especially in the case of data collection systems based on reimbursement data. Underestimation may also have occurred in countries where some psychotropic medicines and medicines with CNS side effects are excluded from the reimbursement lists, but the data collection system of these countries is based on reimbursement data.

Another important point to be considered is the hospital data. As stated above, hospital consumption data were not intended to be included in this study. However, the drug utilization data delivered by Finland, Iceland, Norway and Serbia included hospital data. In Iceland, the hospital data covered approximately $30 \%$ of the total consumption data; in the other three countries, the percentage of coverage could not be assessed. Consequently, drug consumption in these countries may be overestimated.

Bias might also derive from the changes in the ATC or DDD classification of the medicinal drug between 2000 and 2005. Although the data referring to the active substances with a changed ATC code were requested separately, the majority of the countries were not able to provide complete data on the consumption of these substances. Therefore, we were unable to correct for the impact of these changes and, consequently, an underestimation of the use of these medications cannot be completely ruled out. For example, none of the 12 countries was able to provide data on the consumption of levacetylmethadol. This could be due to the fact that this active substance was not marketed or it was not registered in the country (e.g. Hungary and Iceland) or because of the withdrawal of Orlaam ${ }^{\circledR}$ (levacetylmethadol) from the EU market in 2002 by the European Medicines Agency (EMEA) [23]. The consumption of the four active substances whose DDD changed during the study period may also have been misclassified. No specific details on the calculation of the number of DDDs were reported and, therefore, we do not know whether the old or the new DDD was used for this calculation. Other possible sources of bias with respect to the ATC/DDD classification could be associated with the use of different ATC/DDD versions, different DDDs for combination products and the use of unofficial or national DDDs [24].

In light of the above considerations, we can assert that, despite highly developed administrative systems, it is still difficult to collect valid and exhaustive drug utilization data and, therefore, to perform a reliable cross-national comparison in Europe. These findings are consistent with the study carried out by Vander Stichele et al. [25], the rationale of the EURO-MED-STAT project [26] as well as the findings of other authors [24, 27-29].

Our results show that there are large differences in the number of psychotropic drug prescriptions in the $12 \mathrm{EU}$ countries included in our study. Since the validity of the data could not be assessed, it seems reasonable to state that the above-mentioned variations may be due to the different biases which hampered our consumption data. Consequently, it is also possible to conclude that, in this study, patterns of the use of the medicinal products of interest could only be analysed on a national level.

Finally, it is important to highlight that this study did not investigate the correlation between drug utilization patterns and road traffic accidents trends within Europe between 2000 and 2005. However, a recent study of the use of benzodiazepines (BDZs) and driving in Finland may provide insight into this relationship [30]. BDZs are widely used as anxiolytics and hypnotics, and they are also commonly abused drugs [31]. Our findings show a stable use of anxiolytics, hypnotics and sedatives in the period 2000-2005, but, on the other hand, they also show a relatively high use of these drug classes, especially in Scandinavian countries. The Finnish study found an increased trend in driving under the influence of BDZs during the period 2000-2005 [30]. Hence, it could be hypothesized that the observed increase in the use of BDZs may be correlated to the outcomes of our study. Another recent study [32] found a correlation between the prevalence of BDZs among Norwegian drivers and the sales data for these drugs. Similar outcomes also emerged from another study [33] that found a relationship between the number of prescriptions for BDZs in different Norwegian provinces and the frequency of drivers testing positive for BDZs from the same region. One of the issues that emerges from these findings is that the consumption of a number of prescribed drugs as well as of illicit drugs and alcohol represent a real risk for road traffic safety. Consequently, we can conclude that more research is needed to investigate this association.

\section{Conclusions}

A slight increase in the use of psychotropic medicines and medicines with CNS side effects has been observed in an 
earlier study [34], and the results of our study partially confirm this increase. However, since our study did not focus on the association between the prevalence of medicinal products and road traffic accidents, further research is needed to gain a better understanding of the scale of medicinal drug utilization in the driving population and the relation between medicine use and driving. This study also emphasizes that a trustworthy, methodological approach is essential and necessary to ensure the validity, reliability, and homogeneity of the data and enable crossnational comparisons. Improvements should be made in order to obtain better data, and there should be more harmonization of the data collection techniques to establish a reliable epidemiological database. Last, but not least, international collaboration between different countries would be most welcome and is highly recommended.

\begin{abstract}
Acknowledgments For the collection of the consumption data, we would like to thank the participants of the two scientific networks PILLS and EuroDURG. For the clarifications and the suggestions concerning the interpretation of the Norwegian consumption data, we would like to thank Jørgen G. Bramness (Norwegian Institute of Public Health, Norway). This work was carried out with the financial support of the European Commission, under the DRUID Project, 6th Framework Program (Contract No TREN-05-FP6TR-S07.61320518404-DRUID). This report reflects only the authors' view. The European Community is not liable for any use that may be made of the information contained therein.
\end{abstract}

Open Access This article is distributed under the terms of the Creative Commons Attribution Noncommercial License which permits any noncommercial use, distribution, and reproduction in any medium, provided the original author(s) and source are credited.

\section{References}

1. Hedqvist Petersen E (2000) Report on the communication from the Commission to the Council, the European Parliament, the Economic and Social Committee and the Committee of the Regions on "Priorities in EU road safety-progress report and ranking of actions" [COM (2000) 125-C5-0248/2000-2000/2136 (COS)]. Adopted by Parliament on 18 January 2001. Strasbourg

2. Raes E, van den Neste T, Verstraete AG (2008) EMCDDA INSIGHTS: drug use, impaired driving and traffic accidents. EMCDDA, Lisbon. Available at: http://www.emcdda.europa.eu/ publications/insights/driving. Accessed 25 May 2009

3. European Commission (2001) White Paper European Transport Policy for 2010: time to decide. Office for Official Publications of the European Communities, Luxembourg

4. http://www.druid-project.eu. Accessed 15 Sept 2008

5. http://www.eurodurg.com. Accessed 15 Sept 2008

6. http://www.whocc.no/atcddd, The purpose of the ATC/DDD system. Accessed 15 Sept 2008

7. Walsh JM, de Gier JJ, Christopherson AS, Verstraete AG (2004) Drugs and driving. Traffic Inj Prev 5:241-253

8. Barbone F, McMahon AD, Davey PG, Morris AD, Reid IC, McDevitt DG, MacDonald TM (1998) Association of road-traffic accidents with benzodiazepine use. Lancet 352:1331-1336
9. del Río MC, Gómez J, Sancho M, Alvarez FJ (2002) Alcohol, illicit drugs and medicinal drugs in fatally injured drivers in Spain between 1991 and 2000. Forensic Sci Int 127:63-70

10. Hindmarch I (1986) The effect of psychoactive drugs on car handling and related psychomotor ability: a review. In: O'Hanlon JF, de Gier JJ (eds) Drugs and driving. Taylor \& Francis Group, London, pp 71-82

11. Movig KLL, Mathijssen MPM, Nagel PHA, van Egmond T, de Gier JJ, Leufkens HGM, Egberts ACG (2004) Psychoactive substance use and the risk of motor vehicle accidents. Accident Anal Prev 36:631-636

12. Moskowitz H (2004) Antihistamine and driving related behavior: a review of the evidence for impairment. Report number DOT HS 809 073. Available at: http://www.nhtsa.dot.gov/people/injury/ research. Accessed 15 Sept 2008

13. Council Directive 91/439/EEC of 29 July 1991 on driving licences. Official Journal L. 237, 24/08/1991 1-24

14. http://www.whocc.no/atcddd. Alterations in DDDs. Accessed 15 Sept 2008

15. Bruce SE, Vasile RG, Goisman RM, Salzman C, Spencer M, Machan JT, Keller MB (2003) Are Benzodiazepines Still the Medication of Choice for Patients With Panic Disorder With or Without Agoraphobia? Am J Psychiatry 160:14321438

16. Kennedy SH, Lam RW, Cohen NL, Ravindran AV (2001) Clinical guidelines for the treatment of depressive disorders. IV. Medications and other biological treatments. Can J Psychiatry 46[Suppl $1]: 38 \mathrm{~S}-58 \mathrm{~S}$

17. Allgulander C, Bandelow B, Hollander E, Montgomery SA, Nutt DJ, Osaka A, Pollack MH, Stein DJ, Swinson RP (2003) WCA recommendations for the long-term treatment of generalized anxiety disorder. CNS Spectr 8[Suppl 1]:53-61

18. GKV-Modernisierungsgesetz (GMG) 2004 BGB1. I 2190 of 14 November 2003. Available at: http://www.buzer.de/gesetz/7332/ index.htm. Accessed 3 Sept 2008

19. Fuerst J, Kocmur M (2003) Use of psychiatric drugs in Slovenia in comparison to Scandinavian countries. Pharmacoepidemiol Drug Saf 12:399-403

20. World Health Organization (2004) The world medicine situation. Available at: http://apps.who.int/medicinedocs/en/d/Js6160e/10. html. Accessed 26 May 2009

21. Divac N, Toševski DL, Babić D, Djurić D, Prostran M, Samardžić $\mathrm{R}$ (2006) Trends in consumption of psychiatric drugs in Serbia and Montenegro 2000-2004. Pharmacoepidemiol Drug Saf 15:835-838

22. Furtado C, Teixeira I (2006) Utilização de benzodiazepinas em Portugal continental (1999-2003). Acta Med Port 19:239_ 246

23. http://www.emea.europa.eu/pdfs/human/press/pus/877601en.pdf. Accessed 15 Sep 2008

24. Rønning M, Blix HS, Strøm H, Skovlund E, Andersen M, Vander Stichele RH (2003) Problems in collecting comparable national drug use data in Europe: the example of antibacterials. Eu J Clin Pharmacol 58:843-849

25. Vander Stichele RH, Elsevier MM, Ferech M, Blot S, Goossens H, ESAC Project Group (2004) European surveillance of antimicrobial consumption (ESAC): data collection performance and methodological approach. Br J Clin Pharmacol 58:419428

26. http://www.euromedstat.cnr.it/default.asp. Accessed 26 May 2009

27. Cooperstock R, Parnell P (1982) Research on psychotropic drug use. A review of findings and methods. Soc Sci Med 16:11791196

28. World Health Organization (1970) Consumption of drugs. Report on a Symposium convened by the Regional Office for Europe of the WHO. WHO, Copenhagen 
29. Hamunen K, Laitinen-Parkkonen P, Paakkari P, Breivik H, Gordh T, Jensen NH, Kalso E (2002) What do different databases tell about the use of opioids in seven European countries in 2002? Eur J Pain 12:705-715

30. Ojaniemi K, Lintonen T, Impinen AO, Lillsunde PM, Ostamo AI (2009) Trends in driving under the influence of drugs: A registerbased study of DUID suspects during 1977-2007. Accident Anal Prev 41:191-196

31. Bramness JG, Skurtveit S, Mørland J (2002) Clinical impairment of benzodiazepines - relation between benzodiazepine concentrations and impairment in apprenended drivers. Drug Alcohol Depend 68:131-141
32. Gjerde H, Normann PT, Pettersen BS, Assum T, Aldrin M, Johansen U, Kristoffersen L, Øiestad E, Christophersen AS, Mørland J (2008) Prevalence of alcohol and drugs among Norwegian motor vehicle drivers: A roadside survey. Accident Anal Prev 40:1765-1772

33. Skurtveit S, Christophersen AS, Mørland J (1995) Driving under the influence of benzodiazepines: Provincial differences in sale are reflected in drivers suspected of driving under the influence of a drug. Tidsskr Norske Laegeforen 115[Suppl 2]:200-203

34. EMCDDA (2006) Annual report 2006: the state of the drugs problem in Europe 2006. EMCDDA, Lisbon 